\title{
An olive oil-rich diet reduces scavenger receptor mRNA in murine macrophages
}

\author{
Elizabeth A. Miles*, Fiona A. Wallace and Philip C. Calder \\ Institute of Human Nutrition, University of Southampton, Bassett Crescent East, Southampton SO16 7PX, UK
}

(Received 26 January 2000 - Revised 29 June 2000 - Accepted 22 August 2000)

\begin{abstract}
During atherogenesis, a pathological accumulation of lipids occurs within aortic intimal macrophages through uptake of oxidised LDL via scavenger receptors. Here we investigated whether some of the anti-atherosclerotic effects ascribed to an olive oil rich-diet are mediated through effects on macrophage scavenger receptors (MSR). Male C57 B16 mice aged 6 weeks were fed for 12 weeks on a low-fat diet (containing $25 \mathrm{~g}$ corn oil $/ \mathrm{kg}$ ) or on high-fat diets containing $200 \mathrm{~g}$ coconut oil, olive oil or safflower oil $/ \mathrm{kg}$. Thioglycollate-elicited peritoneal macrophages were analysed for fatty acid composition by GC and the levels of mRNA coding for three MSR (MSRA type I, MSRA type II and CD36) were measured by reverse-transcription polymerase chain reaction. Feeding mice diets enriched with different fats resulted in significant differences in the fatty acid profile of macrophages, which reflected the fatty acid compositions of the diets. These differences were accompanied by a lower level of mRNA for MSRA type I, MSRA type II and CD36 in macrophages from mice fed an olive-oil-enriched diet compared with the mice fed on the low-fat diet. These data suggest that part of the protective effect of olive oil against atherosclerosis might be via reducing macrophage uptake of oxidised LDL. Whether this effect is due to the downregulation of gene transcription directly by unsaturated fatty acids or is the result of the effect of monounsaturated fatty acids or other components of olive oil on LDL composition and oxidation remains to be ascertained.
\end{abstract}

Macrophage scavenger receptor: Olive oil: Atherosclerosis: Fatty acid

The Mediterranean diet has been associated with a lower incidence of CHD (Nestle, 1995). In the 'seven countries' study, the protective effects of the Mediterranean diet were partially ascribed to the type, rather than the amount of fat, in the diet (Keys, 1986). The fat of choice in the Mediterranean diet is olive oil (OO), rich in the monounsaturated fatty acid oleic acid (18:1 $n$ 9). Contributory protective effects of $\mathrm{OO}$ against $\mathrm{CHD}$ include beneficial alterations in serum lipid and lipoprotein concentrations (Mattson \& Grundy, 1985; Mensink \& Katan, 1989; Mata et al. 1992; Temme et al. 1996) and increased resistance of LDL to peroxidation (Aviram \& Eias, 1993; Mata et al. 1997).

During early atherogenesis macrophages within the arterial wall take up oxidised LDL via scavenger receptors to become lipid-laden foam cells. These foam cells exert powerful inflammatory and tissue re-modelling effects which contribute to the formation of the atherosclerotic plaque. Macrophage scavenger receptor (MSR) A types I and II are implicated in the pathological deposition of cholesterol during atherogenesis (Hiltunen \& Yla-Herttuala, 1998). Scavenger receptor mRNA is increased in macrophages from aortic intima-medias of rabbits fed on a diet containing $0.1 \mathrm{~g}$ cholesterol/ $\mathrm{kg}$ (Hiltunen et al. 1998) and immunohistochemistry of atherosclerotic lesions from both rabbits and human subjects demonstrates co-localisation of scavenger receptors with oxidised LDL (YlaHerttuala et al. 1991). The role of MSR in diet-induced atherosclerosis in mice was demonstrated by the use of MSR-LDL receptor double knockout mice. These mice had significantly smaller atherosclerotic lesions than LDL receptor single knockout mice. The presence of lesions in the double knockout mice suggested that other LDL scavenger receptors, such as CD36, must also have some role in atherogenesis (Sakaguchi et al. 1998). Given the key role of scavenger receptors in the development of atherosclerosis we hypothesized that part of the protective effect of $\mathrm{OO}$ might be due to an alteration in MSR expression. Therefore, in this study we investigated the effects of diets containing $200 \mathrm{~g}$ OO, safflower oil (SO) or

\footnotetext{
Abbreviations: CO, coconut oil; LF, low fat; MSR, macrophage scavenger receptor; OO, olive oil; SO, safflower oil.

* Corresponding author: Dr Elizabeth Miles, fax + 441703 595489, email: eam@soton.ac.uk
} 
Table 1. Composition of the diets used $(\mathrm{g} / \mathrm{kg})$

\begin{tabular}{lcccc}
\hline Component & LF & CO & OO & SO \\
\hline High-N casein & 200 & 200 & 200 & 200 \\
Sucrose & $295 \cdot 8$ & $295 \cdot 8$ & $295 \cdot 8$ & $295 \cdot 8$ \\
Corn starch & 200 & 200 & 200 & 200 \\
Fibre* & 215 & 50 & 50 & 50 \\
Mineral mix $\dagger$ & 40 & 40 & 40 & 40 \\
DL- $\alpha-$ Tocopherol acetate & $1 \cdot 2$ & $1 \cdot 2$ & $1 \cdot 2$ & $1 \cdot 2$ \\
Vitamin mix $\ddagger$ & 10 & 10 & 10 & 10 \\
L-Methionine & 3 & 3 & 3 & 3 \\
Corn oil & 25 & 10 & 10 & 10 \\
Hydrogenated coconut oil & 0 & 200 & 0 & 0 \\
Olive oil & 0 & 0 & 200 & 0 \\
Safflower Oil & 0 & 0 & 0 & 200 \\
\hline
\end{tabular}

LF, low fat; CO, coconut oil; OO, olive oil; SO, safflower oil.

* Alphacel, a cellulose-based fibre, as recommended by AIN-76.

† AlN-76 containing $(\mathrm{g} / \mathrm{kg})$ : calcium phosphate dibasic 500 , sodium chloride 74 , potassium citrate monohydrate 220 , potassium sulfate 52 , magnesium oxide 24 , manganese carbonate 3.5 , ferric citrate 6 , zinc carbonate 1.6 , cupric carbonate 0.3 , potassium iodate 0.01 , sodium selenite 0.01 , chromium potassium sulfate 0.55 , sucrose 118 .

‡ Containing $(\mathrm{g} / \mathrm{kg})$ retinyl palmitate $1 \cdot 8$, ergocalciferol 0.125 , ascorbic acid 45 , inositol 5, choline chloride 75, menadione 2.25, $p$-aminobenzoic acid 5, niacin $4 \cdot 25$, riboflavin 1 , pyridoxine hydrochloride 1 , thiamine hydrochloride 1 , calcium pantothenate 3 , biotin 0.02 , folic acid 0.09 , vitamin $B_{12} 0.00135$, carrier dextrose 833.46

coconut oil $(\mathrm{CO}) / \mathrm{kg}$ on expression of mRNA for the scavenger receptors MSRA types I and II and CD36 by murine peritoneal macrophages.

\section{Materials and methods}

\section{Animals and diets}

Male C57 B16 mice (Harlan-Olac, Bicester, Oxon., UK) aged 6 weeks were fed on a low-fat diet (containing $25 \mathrm{~g}$ corn oil $/ \mathrm{kg}$ ) or on high-fat diets containing $200 \mathrm{~g} \mathrm{CO}$, OO or SO/kg (ICN Biomedicals, High Wycombe, Bucks., UK). Animals were allowed free access to the diets for 12 weeks ( $n 6$ per diet). The compositions of the diets are shown in Table 1, and the fatty acid compositions of the diets are shown in Table 2. Mice were weighed at weekly intervals. The weight of food consumed was measured every $2 \mathrm{~d}$. Animals were killed by an overdose of $\mathrm{CO}_{2}$. All procedures involving animals were approved by the UK Home Office under the Animals (Scientific Procedures) Act 1986.

\section{Chemicals}

All chemicals were purchased from Sigma (Poole, Dorset, UK) unless otherwise indicated.

Table 2. Fatty acid composition of the diets used ( $g / 100 \mathrm{~g}$ total fatty acid)

\begin{tabular}{lcrrrrrrr}
\hline Diet & $10: 0$ & $12: 0$ & $14: 0$ & $16: 0$ & $16: 1 n 7$ & $18: 0$ & $18: 1 n 9$ & $18: 2 n 6$ \\
\hline LF & nd & 3.4 & 3.5 & 13.7 & nd & 3.3 & 21.9 & 54.3 \\
CO & $6 \cdot 8$ & 56.5 & 17.6 & $7 \cdot 8$ & nd & $5 \cdot 1$ & 2.0 & 2.3 \\
OO & nd & nd & nd & 14.9 & $2 \cdot 2$ & 3.7 & 60.0 & 19.1 \\
SO & 1.6 & 4.3 & 1.1 & 8.7 & nd & 3.9 & 19.4 & 61.0 \\
\hline
\end{tabular}

LF, low fat; CO, coconut oil; OO, olive oil; SO, safflower oil; nd, not detected.

\section{Macrophage preparation}

The mice were injected intraperitoneally with $1 \mathrm{ml}$ Brewer's thioglycollate broth, $4 \mathrm{~d}$ before killing, to elicit macrophage migration to the peritoneal cavity. After death the peritoneal exudate was collected by washing out the peritoneal cavity with $4 \mathrm{ml}$ sterile PBS (Oxoid, Unipath Ltd., Basingstoke, Hants., UK). The cells were washed with sterile PBS, collected by centrifugation, passed through lens tissue (Whatman, Loughborough, Leics., UK) and washed again with sterile PBS. Contaminating erythrocytes were lysed by a $5 \mathrm{~min}$ incubation with Tris-buffered $0.14 \mathrm{mM}-\mathrm{NH}_{4} \mathrm{Cl}, \mathrm{pH} 7 \cdot 2$. The cells were analysed by flow cytometry to assess purity using a macrophage specific antibody (F4/80; Serotec, Oxford, UK). The cells were $>85 \%$ macrophages, with no differences seen between the diets.

\section{Fatty acid analysis}

Total lipid was extracted from macrophages with chloroform-methanol $(2: 1, v / v)$. Fatty acids were prepared by saponification at $70^{\circ} \mathrm{C}$ in methanolic $0.5 \mathrm{mM}-\mathrm{KOH}$. Samples were neutralized using concentrated $\mathrm{H}_{2} \mathrm{SO}_{4}$ and fatty acids were extracted into ethyl acetate. After evaporation to dryness, fatty acid methyl esters were prepared by reaction with an excess of diazomethane in ether. Fatty acid methyl esters (dissolved in hexane) were separated by GC in a Hewlett-Packard 6890 GC fitted with a $25 \mathrm{~m} \times 0.32 \mathrm{~mm}$ BPX70 capillary column, film thickness $0.25 \mu \mathrm{m}$ (Hewlett-Packard, Avondale, PA, USA). The carrier gas was He $(2 \mathrm{ml} / \mathrm{min})$ and the split/splitless injector was used with a split: splitless ratio of 10:1. Injector and detector temperatures were $250^{\circ} \mathrm{C}$ and $270^{\circ} \mathrm{C}$ respectively. The column oven temperature was maintained at $170^{\circ} \mathrm{C}$ for 12 min after sample injection and was programmed to then increase from 170 to $200^{\circ} \mathrm{C}$ at $5^{\circ} \mathrm{C} / \mathrm{min}$ before being maintained at $200^{\circ} \mathrm{C}$ for $15 \mathrm{~min}$. The separation was recorded with Hewlett-Packard GC Chem Station software. Fatty acid methyl esters were identified by comparison with standards analysed previously.

\section{Extraction of RNA and reverse transcription}

Total RNA was extracted from $2 \times 10^{6}$ macrophages using TRIzol (Life Technologies Ltd., Paisley, Scotland, UK) in accordance with the manufacturer's instructions. Messenger RNA was then selectively reverse transcribed using an oligo (dT) primer from $4.5 \mu \mathrm{g}$ total RNA. Reverse transcription was achieved with 7.5 units avian myeloblastosis virus reverse transcriptase (Promega, Southampton, Hants., UK) in the presence of $1 \mathrm{mM}-\mathrm{dNTP}$ (Pharmacia, Milton Keynes, Bucks., UK), $5 \mathrm{~mm}-\mathrm{MgCl}_{2}$ (Promega), RT buffer (10 mM-Tris $\mathrm{HCl}(\mathrm{pH} 8 \cdot 8), 50 \mathrm{mM}-\mathrm{KCl}$ and $0.1 \%$ Triton X-100 (Promega)) and $0.5 \mu \mathrm{g}$ poly (dT) 15 (Promega). RNA was substituted with an equal volume $(5 \mu \mathrm{l})$ diethyl pyrocarbonate (DePc) treated water as a negative control. Reverse transcription was carried out for $1 \mathrm{~h}$ at $42^{\circ} \mathrm{C}$ followed by heating at $94^{\circ} \mathrm{C}$ for $3 \mathrm{~min}$ to inactivate the enzyme. The resulting cDNA was diluted with $15 \mu \mathrm{l}$ 
Table 3. Food and energy intake and weight gain among mice fed on different diets for twelve weeks* (Mean values with their standard errors for six mice per group)

\begin{tabular}{|c|c|c|c|c|c|c|c|c|c|c|}
\hline \multirow[b]{2}{*}{ Diet } & \multicolumn{2}{|c|}{ Start weight $(\mathrm{g})$} & \multicolumn{2}{|c|}{ End weight $(\mathrm{g})$} & \multicolumn{2}{|c|}{ Weight gain (g) } & \multicolumn{2}{|c|}{ Food intake (g/week) } & \multicolumn{2}{|c|}{ Energy intake (kJ/week } \\
\hline & Mean & SE & Mean & SE & Mean & SE & Mean & SE & Mean & SE \\
\hline LF & $22 \cdot 8$ & 0.7 & $25 \cdot 3^{a}$ & 0.2 & $2 \cdot 5^{\mathrm{a}}$ & 0.7 & $30 \cdot 6^{a}$ & 0.3 & $275 \cdot 1^{a}$ & $3 \cdot 2$ \\
\hline $\mathrm{CO}$ & 23.4 & 0.3 & $27 \cdot 3^{b}$ & 0.5 & $3 \cdot 9^{b}$ & 0.4 & $22 \cdot 7^{\mathrm{b}}$ & 0.4 & $433 \cdot 1^{b}$ & 4.6 \\
\hline OO & $23 \cdot 1$ & 0.3 & $31.9^{c}$ & 0.7 & $8 \cdot 8^{c}$ & 0.6 & $24 \cdot 2^{\mathrm{b}}$ & 0.4 & $462 \cdot 4^{c}$ & $6 \cdot 7$ \\
\hline SO & $23 \cdot 0$ & 0.3 & $30 \cdot 5^{c}$ & 0.8 & $7 \cdot 5^{\mathrm{c}}$ & 0.7 & $23 \cdot 8^{b}$ & 0.3 & $454 \cdot 0^{\mathrm{C}}$ & $4 \cdot 8$ \\
\hline
\end{tabular}

LF, low fat; CO, coconut oil; OO, olive oil; SO, safflower oil.

a,b,cMean values within a column with unlike superscript letters were significantly different (ANOVA, $P<0.05$ ).

${ }^{*}$ For details of diets, see Tables 1 and 2.

DePc treated water to a final volume of $35 \mu l$ and used as a polymerase chain reaction template.

\section{DNA amplification and visualization}

Polymerase chain reaction was performed for a housekeeping gene (cyclophilin), MRSA type I, MRSA type II and CD36. Amplification of $2.5 \mu \mathrm{l}$ cDNA was achieved using 1 unit Taq polymerase in the presence of $15 \mathrm{pmol}$ both primers, $\mathrm{Mg}$-free buffer (19 mM-Tris- $\mathrm{HCl}$ (pH 9.0), $50 \mathrm{mM}-\mathrm{KCl}$ and $0.1 \%$ Triton X-100 (Promega)), $1.5 \mathrm{~mm}-$ $\mathrm{MgCl}_{2}$ (Promega) and $0.2 \mathrm{mM}-\mathrm{dNTP}$ (Pharmacia). The reaction cycling was $95^{\circ} \mathrm{C}$ for $30 \mathrm{~s}, 56^{\circ} \mathrm{C}\left(50^{\circ} \mathrm{C}\right.$ for CD36) for $30 \mathrm{~s}$ and $72^{\circ} \mathrm{C}$ for $1 \mathrm{~min}$ in a Hybaid Touchdown Thermocycler (Hybaid, Teddington, Middlesex, UK). The optimised number of cycles used was twenty-six for MRSA type I and type II and twenty-three cycles for CD36. The primer sequences used for cyclophilin were $5^{\prime}$ TTGGGTCGCGTCTCGTTCGA- $3^{\prime}$ sense and $5^{\prime}$-GCCAGGACCTGTATGCTTCA-3' antisense. Primers for MSRA type I were $5^{\prime}$-GGGAGACAGAGGGCTTACTGG A-3' sense and $5^{\prime}$-TTGTCCAAAGTGAGCTCTCTTG-3' antisense (389 base pairs). Primers used for MSRA type II were $5^{\prime}$-GGGAGACAGAGGGCTTACTGGA-3' sense and $5^{\prime}$-ATGTTCAGGGAGTTATACTGATC- $3^{\prime}$ antisense (223 base pairs). Primers used for CD36 were $5^{\prime}$-GTTTTA TCCTTACAATGACA- ${ }^{\prime}$ sense $5^{\prime}$-GGAAATGTGGAA GCGAAATA-3' antisense (420 base pairs). Polymerase chain reaction products were electrophoresed on $2 \%$ agarose gels stained with ethidium bromide. The resultant bands were visualised with an u.v. transilluminater and the image stored with a GDS 5000 gel documentation system (UVP, Cambridge, UK). The images were then analysed by densitometry using Phoretix 2D 4.00 software (Phoretix International Ltd, Newcastle upon Tyne, UK). All results are expressed as scavenger receptor: cyclophilin mRNA ratio where the test cDNA was amplified for cyclophilin concurrently with amplification for the scavenger receptors and under the same conditions.

\section{Data analysis}

All data are expressed as mean values with their standard errors for $n$ observations. Data were analysed using a oneway ANOVA with a post-hoc least significant difference test using SPSS version 6.1 for Windows (SPSS Inc.,
Chicago, IL, USA). Differences with $P<0.05$ were considered significant.

\section{Results \\ Food, energy and fatty acid intake and weight gain}

Fat absorption was greater than $95 \%$ as judged by faecal fat content, and was not different among mice fed on the different diets (data not shown). Mice fed on the low-fat (LF) diet consumed more food than those fed on each of the high-fat diets (Table 3); food intake did not differ among mice fed on the $\mathrm{CO}$, OO or SO diets. Due to the higher energy density of the high-fat diets, mice fed on those diets consumed more energy than those fed on the LF diet (Table 3). The intakes of individual fatty acids differed among mice fed the different diets. Mean total saturated fatty acid intakes among mice fed the different diets were 0.16 (LF), $4.31(\mathrm{CO}), 0.86(\mathrm{OO})$ and $0.93(\mathrm{SO}) \mathrm{g} /$ week, while mean oleic acid intakes were 0.16 (LF), 0.08 (CO), 3.10 (OO) and 1.04 (SO) g/week. Mean linoleic acid intakes among mice fed the different diets were 0.40 (LF), 0.11 (CO), 0.77 (OO) and 2.78 (SO) g/week.

There were no differences in the weights of the mice in the different groups prior to feeding on the different diets (Table 3). However, mice fed on the high-fat diets gained more weight than those fed on the LF diet (Table 3), such that at the end of the feeding period the weights of the mice fed on the $\mathrm{CO}, \mathrm{OO}$ or SO diets were greater than those of mice fed on the LF diet (Table 3).

\section{Fatty acid composition of macrophages}

Macrophages from the CO-fed mice had a significantly higher proportion of 14:0 when compared with macrophages from the mice fed the other diets (Table 4). Macrophages from mice fed the OO diet had the lowest proportion of the saturated fatty acids 14:0, 16:0, 17:0 and 18:0. OO feeding resulted in macrophages with a significantly higher proportion of the monounsaturated fatty acids 18:1 $n 9$ and 20:1 $n 9$ compared with the other diets. The proportion of 18:1 $n 9$ was 1.9 times greater in the macrophages from $\mathrm{OO}$ than from LF- or CO-fed mice and 2.7 times greater than in macrophages from SO-fed mice. Macrophages from OO-fed mice had the lowest proportion of 20:4 $n 6$, which was significantly lower than in the LF-fed mice. Macrophages from the OO-fed mice 
Table 4. Fatty acid composition ( $g / 100 \mathrm{~g}$ total fatty acids) of peritoneal macrophages from mice fed a low-fat diet or high-fat diets containing coconut oil, olive oil or safflower oil for 12 weeks ${ }^{*}$ (Mean values with their standard errors for three to six mice per group)

\begin{tabular}{|c|c|c|c|c|c|c|c|c|}
\hline \multirow{2}{*}{$\begin{array}{l}\text { Diet.... } \\
\text { Fatty acid }\end{array}$} & \multicolumn{2}{|c|}{ LF } & \multicolumn{2}{|c|}{$\mathrm{CO}$} & \multicolumn{2}{|c|}{ OO } & \multicolumn{2}{|c|}{ so } \\
\hline & Mean & SE & Mean & SE & Mean & SE & Mean & \\
\hline 4:0 & $0.5^{* \mathrm{~b}}$ & 0.5 & $3 \cdot 4^{a}$ & 0.4 & $0.4^{\mathrm{b}}$ & 0.2 & $0.7^{\mathrm{b}}$ & \\
\hline 16: & $22 \cdot 4^{\mathrm{a}}$ & & $21.9^{a b}$ & & $18 \cdot 5^{\mathrm{b}}$ & & $21 \cdot 0^{\mathrm{ab}}$ & \\
\hline $16: 1 \cap 7$ & $1.9^{\mathrm{ab}}$ & 0 . & $3 \cdot 3^{a}$ & 0 . & $1.8^{\mathrm{ab}}$ & 0.3 & $\mathrm{nd}^{\mathrm{b}}$ & \\
\hline $17: 0$ & 0.2 & 0 . & 0.3 & 0.3 & nd & & 0.4 & \\
\hline 18:0 & $16 \cdot 7^{\mathrm{ab}}$ & 0.6 & $18 \cdot 9^{a}$ & 1.9 & $13 \cdot 3^{b}$ & 0.8 & $18 \cdot 3^{a}$ & \\
\hline 18 & $16 \cdot 2^{\mathrm{b}}$ & 0 . & $15 \cdot 8^{b}$ & 0 & $31 \cdot 1^{a}$ & & $11 \cdot 7^{\mathrm{C}}$ & \\
\hline 18:1 $n$ & & 0 & 4.8 & $1 \cdot 2$ & 3.7 & $\cdot 1$ & $2 \cdot 4$ & \\
\hline $18: 2$ n 6 & $13 \cdot 1^{\mathrm{b}}$ & 0.3 & $10 \cdot 3^{c}$ & 0.4 & $9 \cdot 8^{c}$ & 0.4 & $24 \cdot 7^{a}$ & \\
\hline $20: 1 n 9$ & $n d^{b}$ & & $\mathrm{nd}^{\mathrm{b}}$ & & $0.8^{\mathrm{a}}$ & 0.4 & $\mathrm{nd}^{\mathrm{b}}$ & \\
\hline $20: 2 n 6$ & nd & & nd & & nd & & 0.8 & \\
\hline $20: 3 n 6$ & $0.9^{b}$ & 0.4 & $1.2^{a b}$ & 0.5 & $1.6^{\mathrm{ab}}$ & 0.1 & $2 \cdot 1^{\mathrm{a}}$ & \\
\hline $20: 4 n 6$ & $22 \cdot 0^{a}$ & 1.0 & $19 \cdot 0^{\mathrm{b}}$ & 0.9 & $16 \cdot 1^{\mathrm{b}}$ & 1. & $17 \cdot 5^{\mathrm{b}}$ & \\
\hline $24: 0$ & 0.8 & 0. & 0.3 & 0.5 & 1.0 & 0.5 & 0.4 & \\
\hline $22: 5 n 3$ & 0.3 & 0.3 & 0.2 & 0.2 & nd & & nd & \\
\hline $22: 6 n 3$ & $0.9^{a, b}$ & 0.7 & $0.6^{b}$ & $0 . \overline{6}$ & $1.9^{a}$ & 0.1 & $n d^{b}$ & \\
\hline
\end{tabular}

LF, low fat; CO, coconut oil; OO, oilve oil; SO, safflower oil; nd, not detected. * For details of diets, see Tables 1 and 2 .

${ }^{a, b, c}$ Mean values within a row with unlike superscript letters were significantly different (ANOVA, $P<0.05$ ).

had the highest proportion of 22:6 $n 3$ compared with macrophages from the mice on the other diets. SO feeding resulted in macrophages with significantly lower proportions of 18:1 $n 9$ compared with those of mice fed each of the other high-fat diets. The proportions of the $n 6$ polyunsaturated fatty acids 18:2 $n 6,20: 2 n 6$ and 20:3 $n 6$ were higher in macrophages from SO-fed mice than those from the mice fed on the other diets and this was significant for 18:2 $n 6$. Mice fed the SO diet had macrophages with the lowest proportion of 22:6 $n 3$ compared with macrophages from those fed the LF, $\mathrm{CO}$ and $\mathrm{OO}$ diet.

\section{Macrophage scavenger receptor $m R N A$}

Reverse-transcription polymerase chain reaction products (Fig. 1) were visualised by agarose gel electrophoresis and measured by densitometry. Results are shown as the scavenger receptor mRNA:constitutively expressed cyclophilin mRNA ratio (Figs. 2-4). RNA harvested from freshly isolated macrophages from mice fed on the OO-rich diet had significantly less mRNA specific for MSRA type I than macrophages from mice fed on the CO or LF diets (Fig. 2). Feeding the $\mathrm{CO}$ or SO diets did not affect the MRSA type I:cyclophilin mRNA ratio compared with feeding the LF diet (Fig. 2). Macrophages from mice fed on the OO diet had significantly less mRNA for MRSA type II than those from mice fed on the LF diet (Fig. 3). This was also lower than found in cells from mice fed on the other high-fat diets although this did not reach significance. Messenger RNA for MRSA type II was not altered by feeding on the high-fat diets containing $\mathrm{CO}$ and $\mathrm{SO}$ when compared with feeding the LF diet (Fig. 3). Macrophages from mice fed the $\mathrm{OO}$ diet had significantly less mRNA specific for the scavenger receptor CD36 when compared with macrophages from mice fed the LF diet (Fig. 4). The CD36:cyclophilin mRNA ratio did not differ for the CO-, SO- and LF-fed mice.

\section{Discussion}

The role of the MSR in the development of atherosclerotic lesions has been well-documented (Hiltunen \& YlaHerttuala, 1998). The importance of scavenger receptors in the development of diet-induced atherosclerosis was indicated in a recent study where MSRA-LDL receptor double knock out mice developed significantly less extensive and severe plaques when compared with LDL receptor knock out mice (Sakaguchi et al. 1998). Several mechanisms for the anti-atherogenic effects of a diet rich in OO have been proposed. These effects include beneficial

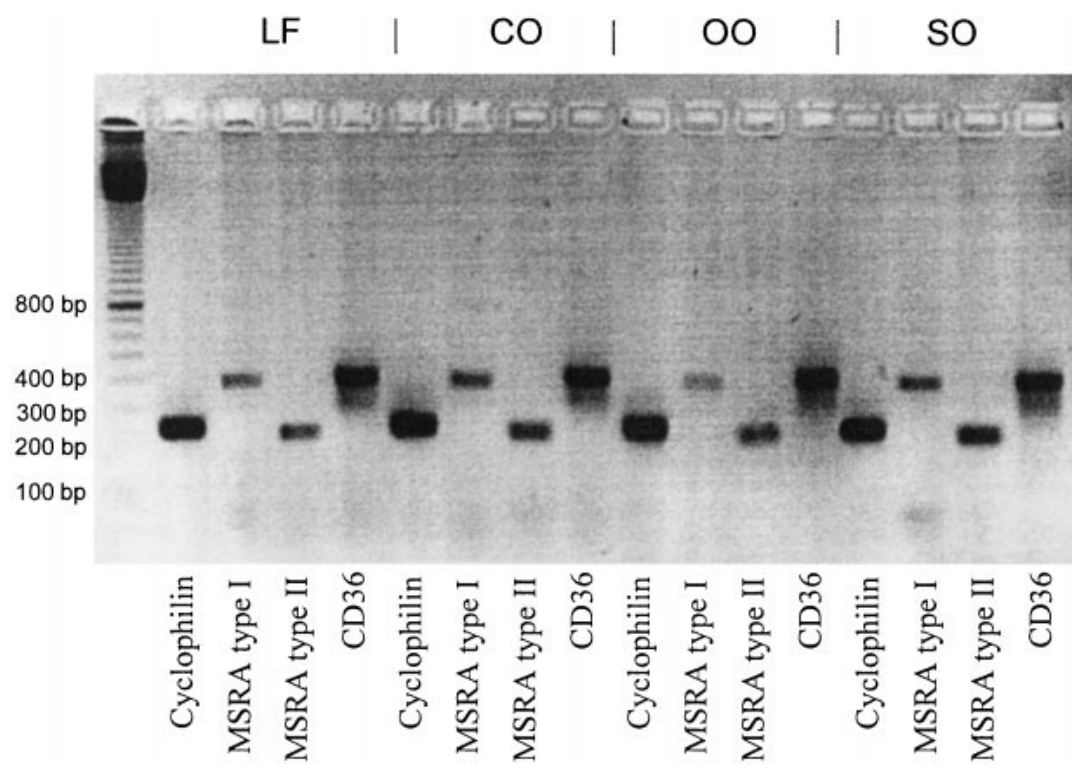

Fig. 1. Polymerase chain reaction products from murine peritoneal macrophages from mice fed a low-fat (LF) diet or high-fat diets containing coconut oil (CO), olive oil (OO) or safflower oil (SO) for 12 weeks. For details of diets, see Tables 1 and 2, and for details of procedures, see pp. 186-187. Bands from left to right for cyclophilin, macrophage scavenger receptor (MSR) A type I, MSRA type II and CD36. bp, base pairs. 


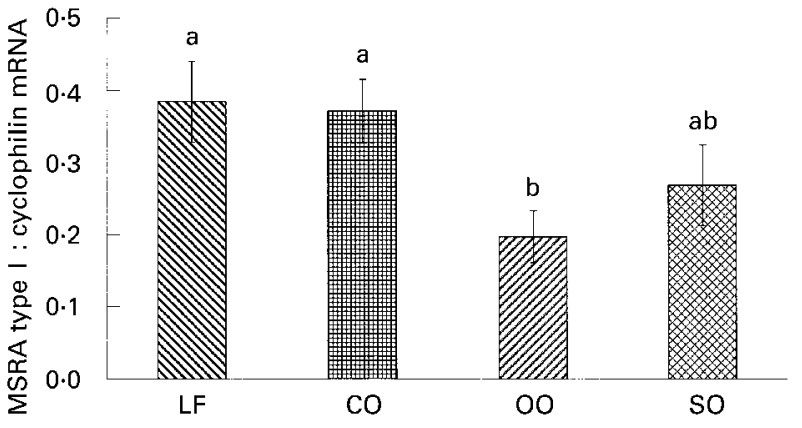

Fig. 2. Macrophage scavenger receptor (MSR) A type I mRNA expression in macrophages from mice fed a low-fat (LF) diet or highfat diets containing coconut oil (CO), olive oil (OO) or safflower oil (SO) for 12 weeks. For details of diets, see Tables 1 and 2, and for details of procedures, see pp. 186-187. Values are means for six mice per group with standard errors represented by vertical bar. ${ }^{\mathrm{a}, \mathrm{b}}$ Values with unlike letters were significantly different (ANOVA, $P<0.05)$.

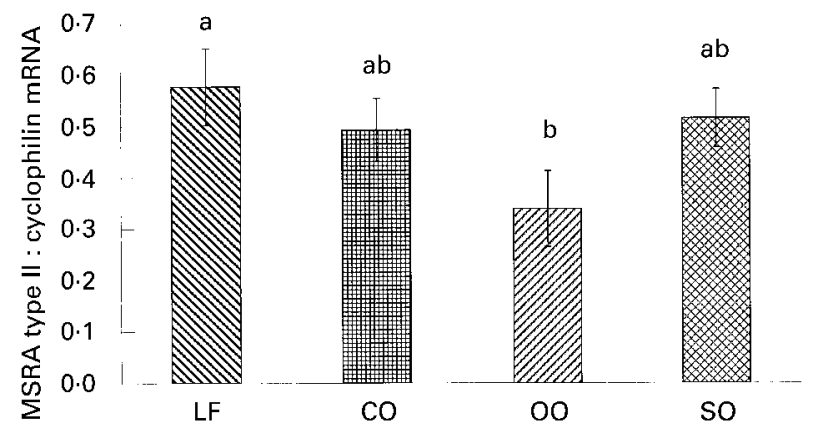

Fig. 3. Macrophage scavenger receptor (MSR) A type II mRNA expression in macrophages from mice a low-fat (LF) diet or high-fat diets containing coconut oil (CO), olive oil (OO) or safflower oil (SO) for 12 weeks. For details of diets, see Tables 1 and 2, and for details of procedures, see pp. 186-187. Values are means for six mice per group with standard errors represented by vertical bars. ${ }^{a, b}$ Values with unlike letters were significantly different (ANOVA $P<0.05$ ).

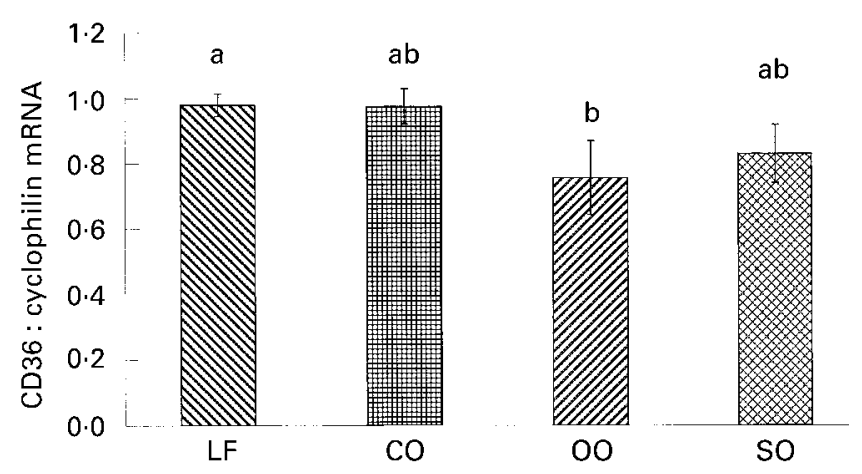

Fig. 4. CD36 mRNA expression in macrophages from mice fed a low-fat (LF) diet or high-fat diets containing coconut oil (CO), olive oil (OO) or safflower oil (SO) for 12 weeks. For details of diets, see Tables 1 and 2, and for details of procedures, see pp. 186-187. Values are means for six mice per group with standard errors represented by vertical bars. ${ }^{a, b}$ Values with unlike letters were significantly different (ANOVA $P<0.05$ ). alterations in plasma lipoprotein concentrations (Mata et al. 1992), and a reduction in plasma LDL oxidation (Scaccini et al. 1992), perhaps due to an increased resistance of LDL to peroxidation (Aviram \& Eias, 1993; Mata et al. 1997; Scaccini et al. 1992). There was a reduction in the accumulation of cholesterol in the aortas of rabbits fed on an atherogenic diet when $\mathrm{OO}$ was added to the diet (Mortensen et al. 1992). The latter could result from decreased LDL oxidation or decreased ability to take up oxidised LDL or both. In this present study we investigate whether some of the beneficial effects of a high $\mathrm{OO}$ diet may be mediated via an effect on macrophage scavenger receptors.

Feeding male C57B16 mice for 12 weeks on high-fat diets enriched with different fats resulted in significant differences in the fatty acid profile of peritoneal macrophages, which reflected the fatty acid compositions of the diets. Macrophages from the mice maintained on the OOrich diet had a greater proportion of monounsaturated fatty acids and the mice maintained on the SO-rich diet had a greater proportion of $n 6$ polyunsaturated fatty acids. The peritoneal macrophages used in the current study are derived from circulating monocytes recruited to the peritoneal cavity following the intraperitoneal administration of thioglycollate. The fatty acid composition of circulating and tissue monocytes and macrophages may be changed through a variety of mechanisms. These will relate to the fatty acid compositions of circulating lipids, which are readily changed according to diet. Monocytes and macrophages are able to take up non-esterified fatty acids directly (Calder et al. 1990) and are also able to hydrolyse triacylglycerol-rich lipoproteins making their constituent fatty acids accessible (Mahoney et al. 1982). In addition, monocytes and macrophages express receptors for a variety of lipoproteins and so can take up intact lipoproteins by the process of receptor-mediated endocytosis (Goldstein et al. 1979, 1980). Finally, direct exchange of fatty acids between the monocyte or macrophage plasma membrane and various circulating lipids (e.g. cholesterol esters, phospholipids) can occur by virtue of transfer proteins.

Scavenger receptor mRNA expression was lower in freshly isolated macrophages from mice maintained on the OO diet when compared with the LF diet. This was apparent for all three scavenger receptors investigated (MSRA type I, MSRA type II, CD 36). In addition, MRSA type I mRNA expression was lower after OO feeding than after $\mathrm{CO}$ feeding. Since mRNA levels for scavenger receptors are likely to be related to cell surface expression of these receptors and so uptake of modified LDL, these data suggest that one effect of $\mathrm{OO}$ in protection against atherosclerosis might be a reduction in ability of macrophages within the lesion to take up oxidised LDL. The transcription and expression of scavenger receptors can be induced by oxidised LDL (Han \& Nicholson, 1998; Nagy et al. 1998; Yoshida et al. 1998). The presence of oxidised LDL in atherosclerotic lesions has been demonstrated and this co-localizes with scavenger receptor expression (YlaHerttuala et al. 1991). Our results suggest that a diet rich in $\mathrm{OO}$ attenuates the signal to the macrophage, which induces scavenger receptor gene expression and therefore reduces 
the level of mRNA coding for scavenger receptors within these macrophages. OO may act in a number of ways on this signal. OO may reduce the oxidation of LDL either in the plasma or within the intima tissues. Several studies have demonstrated that LDL from animals or human subjects fed on an OO-rich diet are more resistant to peroxidation (Scaccini et al. 1992; Aviram \& Eias, 1993, Mata et al. 1997). The OO-rich diet also resulted in the lowest proportion of linoleic acid in the macrophages in this study (Table 4) and has been reported to decrease the content of linoleic acid in plasma lipoproteins (RuizGutierrez et al. 1998). A recent study has demonstrated that two oxidative metabolites of linoleic acid (9-hydroxyoctadecadienoic acid and 13-hydroxyoctadecadienoic acid) mediate the signal between oxidised LDL and MSRA and CD36 gene transcription (Nagy et al. 1998). Thus, a reduction in the amount of linoleic acid may also affect levels of scavenger receptor mRNA in macrophages. Unsaturated fatty acids have been demonstrated to affect gene transcription (for review, see Sessler \& Ntambi, 1998). The reduction of pro-atherogenic surface molecules, such as vascular cell adhesion molecule 1 by human endothelial cells cultured with oleic acid or docosahexaenoic acid has been previously demonstrated (De Caterina et al. 1994). The effects of these unsaturated fatty acids occurred at the mRNA level with reduction in vascular cell adhesion molecule 1 mRNA accumulation (De Caterina et al. 1994, 1998). Culturing with docosahexaenoic acid has also been shown to reduce mRNA and surface expression of CD36 in the human monocytic cell line U937 (Pietsch et al. 1995). Furthermore dietary fish oil, which is a rich source of docosahexaenoic acid, reduces the level of mRNA coding for several pro-inflammatory cytokines in murine macrophages and also reduced the development of diet-induced atherosclerotic lesions (Renier et al. 1993). In our present study feeding an OO-rich diet, while significantly increasing the proportion of oleic acid, also increased the docosahexaenoic acid content of the macrophages when compared with the other diets. Such increases in docosahexaenoic acid content in tissue lipids after feeding an OO-rich diet have been previously demonstrated in rats (Navarro et al. 1992, 1994). The increase of these unsaturated fatty acids in the murine macrophages may result in the lower accumulation of scavenger receptor mRNA in the macrophages from the OO-fed mice when compared with those from mice on the other diets.

Given the role of scavenger receptor in foam cell formation and atherogenesis, we feel this may contribute to the anti-atherosclerotic properties ascribed to a high-OO diet. This is the first time that the feeding of dietary OO has been demonstrated to reduce the steady state level of mRNA of the MSR. Whether this effect is due to the downregulation of gene transcription directly by unsaturated fatty acids or the effect of monounsaturated fatty acids or other components of OO on LDL composition and oxidation remains to be ascertained.

\section{Acknowledgements}

We thank Professor S. Gordon at the William Dunn School of Pathology, University of Oxford, UK, for providing the sequences for the MSRA type I and type II primers for the polymerase chain reaction. This research was funded by the Biotechnology and Biological Sciences Research Council, UK under the Nutrient-Gene Interaction initiative (Grant no. 51/FO5696). Fiona Wallace held a Rank Prize Fund Studentship.

\section{References}

Aviram M \& Eias K (1993) Dietary olive oil reduces low-density lipoprotein uptake by macrophages and decreases the susceptibility of the lipoprotein to undergo lipid peroxidation. Annals of Nutrition and Metabolism 37, 75-84.

Calder PC, Bond JA, Harvey DJ, Gordon S \& Newsholme EA (1990) Uptake and incorporation of saturated and unsaturated fatty acids into macrophage lipids and their effect upon macrophage adhesion and phagocytosis. Biochemical Journal 269, 807-814.

De Caterina R, Bernini W, Annunziata Carluccio M, Liao JK \& Libby P (1998) Structural requirements for inhibition of cytokine induced endothelial activation by unsaturated fatty acids. Journal of Lipid Research 39, 1062-1070.

De Caterina R, Cybulsky MI, Clinton SK, Gimbrone MA Jr \& Libby P (1994) The omega-3 fatty acid docosahexaenoate reduces cytokine-induced expression of proatherogenic and proinflammatory proteins in human endothelial cells. Arteriosclerosis and Thrombosis 14, 1826-1836.

Goldstein JL, Ho YK, Brown MS, Innerarity TL \& Mahley RW (1980) Cholesteryl ester accumulation in macrophages resulting from receptor-mediated uptake and degradation of hypercholesterolemic canine beta-very low density lipoproteins. Journal of Biological Chemistry 255, 1839-1848.

Goldstein JL, Ho YK, Basu SK \& Brown MS (1979) Binding site on macrophages that mediates uptake and degradation of acetylated low density lipoprotein, producing massive cholesterol accumulation. Proceedings of the National Academy of Sciences, USA 76, 333-337.

Han J \& Nicholson AC (1998) Lipoproteins modulate expression of the macrophage scavenger receptor. American Journal of Pathology 152, 1647-1654.

Hiltunen TP, Luoma JS, Nikkari T \& Yla-Herttuala S (1998) Expression of LDL receptor, VLDL receptor, LDL receptorrelated protein, and scavenger receptor in rabbit atherosclerotic lesions. Circulation 97, 1079-1086.

Hiltunen TP \& Yla-Herttuala S (1998) Expression of lipoprotein receptors in atherosclerotic lesions. Atherosclerosis 137, Suppl. S81-S88.

Keys A (1986) The diet and 15-year death rate in the seven countries study. American Journal of Epidemiology 124, 903 915.

Mahoney EM, Khoo JC \& Steinberg D (1982) Lipoprotein lipase secretion by human monocytes and rabbit alveolar macrophages in culture. Proceedings of the National Academy of Sciences, USA 79, 1639-1642.

Mata P, Alvarez-Sala LA, Rubio MJ, Nuno J \& De Oya M (1992) Effects of long-term monounsaturated- vs polyunsaturatedenriched diets on lipoproteins in healthy men and women. American Journal of Clinical Nutrition 55, 846-850.

Mata P, Varela O, Alonso R, Lahoz C, De Oya M \& Badimon L (1997) Monounsaturated and polyunsaturated $n-6$ fatty acidenriched diets modify LDL oxidation and decrease human coronary smooth muscle cell DNA synthesis. Arteriosclerosis Thrombosis and Vascular Biology 17, 2088-2095.

Mattson FH \& Grundy SM (1985) Comparison of the effects of dietary saturated, mono-unsaturated, and poly-unsaturated 
fatty-acids on plasma-lipids and lipoproteins in man. Journal of Lipid Research 26, 194-202.

Mensink RP \& Katan MB (1989) Effects of a diet enriched with monounsaturated or polyunsaturated fatty acids on levels of low density and high density lipoproteins cholesterol in healthy women and men. New England Journal of Medicine 17, 436441.

Mortensen A, Espensen PL, Fischer Hansen B \& Ibsen P (1992) The influence of dietary olive oil and margarine on aortic cholesterol accumulation in cholesterol-fed rabbits maintained at similar plasma cholesterol level. Atherosclerosis 96, 159170.

Nagy L, Tontonez P, Alvarez JGA, Chen H \& Evans RM (1998) Oxidised LDL regulates macrophage gene expression through ligand activation of PPAR $\gamma$. Cell 93, 229-240.

Navarro MD, Hortelano P, Periago JL \& Pita ML (1992) Effect of dietary olive and sunflower oils on the lipid composition of the aorta and platelets and on blood eicosanoids in rats. Arteriosclerosis and Thrombosis 12, 830-835.

Navarro MD, Periago JL, Pita ML \& Hortelano P (1994) The $n-3$ polyunsaturated fatty acid levels increase in response to dietary olive oil relative to sunflower oil. Lipids 29, 845-849.

Nestle M (1995) Mediterranean diets: historical and research overview. American Journal of Clinical Nutrition 61, Suppl. 1313S-1320S.

Pietsch A, Weber C, Goretski M, Weber PC \& Lorenz RL (1995) $n-3$ but not $n-6$ fatty acids reduce the expression of the combined adhesion and scavenger receptor CD36 in human monocytic cells. Cell Biochemistry and Function 13, 211-216.

Renier G, Skamene E, DeSanctis J \& Razioch D (1993) Dietary n3 polyunsaturated fatty acids prevent the development of atherosclerotic lesions in mice. Modulation of macrophage secretory activities. Arteriosclerosis and Thrombosis 13, 15151524.

Ruiz-Gutierrez V, Morgado N, Prada JL, Perez-Jimenez F \& Muriana FJG (1998) Composition of human VLDL triacylglycerols after ingestion of olive oil and high oleic acid sunflower oil. Journal of Nutrition 128, 570-576.

Sakaguchi H, Takeya M, Suzuki H, Hakamata H, Kodama T, Horiuchi S, Gordon S, van der Laan LJW, Kraal G, Ishibashi S, Kitamura N \& Takahashi K (1998) Role of macrophage scavenger receptors in diet-induced atherosclerosis in mice. Laboratory Investigation 78, 423-434.

Scaccini C, Nardini M, D’Aquino M, Gentili V, Di Felice M \& Tomassi G (1992) Effect of dietary oils on lipid peroxidation and on antioxidant parameters of rat plasma and lipoprotein fractions. Journal of Lipid Research 33, 627-633.

Sessler AM \& Ntambi JM (1998) Polyunsaturated fatty acid regulation of gene expression. Journal of Nutrition 128, 923926.

Temme EHM, Mensink RP \& Hornstra G (1996) Comparison of the effects of diets enriched in lauric, palmitic, or oleic acids on serum lipids and lipoproteins in healthy women and men. American Journal of Clinical Nutrition 63, 897-903.

Yla-Herttuala S, Rosenfeld ME, Parthasarathy S, Sigal E, Sarkiola T, Witztum JL \& Steinberg D (1991) Gene expression in macrophage-rich human atherosclerotic lesions: 15-lipoxygenase and acetyl low density lipoprotein receptor messenger RNA colocalize with oxidation specific lipid-protein adducts. Journal of Clinical Investigation 87, 1146-1152.

Yoshida H \& Quehenberger OKondratenko NGreen SSteinberg D (1998) Minimally oxidised low-density lipoprotein increases expression of scavenger receptor A, CD36, and macrosialin in resident mouse peritoneal macrophages. Arteriosclerosis Thrombosis Vascular Biology 18, 794-802. 